\title{
Trafegar entre territórios e secundaristas: Educação Física, política e ocupação
}

\author{
Vivian Marina Redi Pontin'
}

\begin{abstract}
RESUMO
O propósito desse trabalho é trazer à tona uma discussão a respeito das ocupações em escolas que têm acontecido no Brasil nos últimos anos. Sua relação com o Ensino Médio é por conta de um protagonismo esboçado em tais ocupações e que ganha visibilidades e dizibilidades. A palavra secundarista é aqui convocada como uma espécie de chamamento e de conexão entre política e educação física. Política aqui entendida como ocupação dos sentidos, distribuição do sensível e de um comum. Cria-se, pois, uma política menor de educação com intuito de deslocar o que olhar e dizer com as ocupações. Ela não está pautada num fim, numa (re)solução, mas em problematizar intoleráveis. A potência da educação física, nesse sentido, pode estar em se valer da premissa de que cuida do corpo e passar a se responsabilizar por tal afirmação, ao escolher os afetos como aquilo a que é preciso estar atenta.
\end{abstract}

Palavras-chave: Corpo. Educação. Política

1 Doutora em Ciências Sociais. Pesquisadora colaboradora do Labjor Universidade Estadual de Campinas (UNICAMP). Campinas/São Paulo, Brasil. E-mail: vivian_marina@yahoo.com.br. 
To traffic between territories and high school students: Physical Education, politics and occupation

\begin{abstract}
The purpose of this work is to bring up a discussion about the occupations in schools that have been happening in Brazil in recent years. Its relation with High School is due to a protagonist sketched in such occupations and that gains visibilities and something sayable. The high school student is brought here as a kind of call and connection between politics and physical education. Politics understood here as occupation of the senses, distribution of the sensible and of a common. A minor education policy is therefore created with the aim of dislocating what you look at and say with occupations. It isn't based on an end, on (re)solution, but on questioning intolerables. The power of physical education, in this sense, can be based on the premise that it takes care of body and takes responsibility for that affirmation, choosing affections as what needs to be attentive.
\end{abstract}

Keywords: Body. Education. Politic

La viaje entre territorios y los secundarios: Educación Física, política y ocupación

\title{
RESUMEN
}

El propósito de este trabajo es Ilevar a una discusión de las ocupaciones en las escuelas que han tenido lugar en Brasil actualmente. Su relación con la escuela secundaria se debe a una función que gaña visibilidad y dizibilidad. La palabra secundario aquí se denomina como una especie de llamada y la conexión entre la política y la educación física. Política entiende acá como la ocupación de los sentidos, la distribución sensible y de lo común. Por lo tanto, crea una política de educación menor con el objetivo de cambiar lo que debe buscar y decir con las ocupaciones. No es guiado en orden, una (re)solución, pero intolerable para ser interrogados. El poder de la educación física en este sentido puede se confiar en la premisa de que se encarga del cuerpo y tomar la responsabilidad de tal declaración al elegir los afectos como lo que hay que tener cuidado.

Palabras clave: Cuerpo. Educación. Política 


\section{INTRODUÇÃO}

As ocupações em escolas que têm ocorrido no Brasil, especialmente entre 2015 e 2016, não são exclusivas, ou não são exclusividade do Ensino Médio, no entanto, há, ali, uma espécie de protagonismo que se gostaria de ressaltar. O propósito deste texto é, pois, explorar o que o termo ocupação pode ganhar de sentido quando inserido no contexto escolar. Para isso, buscar-se-á algumas formas de expressão de ocupações, as quais contribuem para um pensamento, enquanto percepção de um mundo e o que pode um corpo e os afetos que o percorrem.

Se num primeiro momento o leitor ou a leitora achar que essas coisas estão muito distantes - ocupação e escola; formas de expressão e ocupação; pensamento e percepção de mundo; corpo, afeto e ocupação; ocupação e educação; ocupação e território; ocupação e educação física - enfim, uma série de palavras que parecem desconexas, não abandone este convite de leitura. A escrita escolheu uma vagarosidade para explorar tais palavras e, aos poucos, as alianças aparecerão. Alianças como elos que ligam os termos sem torná-los refém de uma submissão ou dominação de um termo sobre outro. Os elos ligam mantendo as singularidades de cada palavra, preocupando-se em mantê-las distintas e, no entanto, com um problema em comum.

Em termos de procedimentos, o texto se divide em reflexões com as ocupações, tendo as artes e a própria escola em conexão com uma ideia de espaço público e de cidade, ressaltando uma política do comum. A partir do estopim das reflexões, far-se-á, ao final uma relação entre ocupação e educação física tendo o corpo e os afetos como disparadores.

Das coisas que pareciam distantes - série de palavras desconexas - cada um dos pares compõem uma parte do texto, em que se gesta uma escrita interessada em ocupações: "o ato de escrever é uma maneira de ocupar o sensível e de dar sentido a essa ocupação" (RANCIÈRE, 1995, p. 7) e em vez de fechar os termos e chegar num consenso, a tentativa é de multiplicar o que pode uma ocupação a medida em que se compartilha seus sentidos. Uma política.

\section{OCUPAÇÃO E ESCOLA / OCUPAÇÃO E EDUCAÇÃO}

O movimento ficou conhecido pela palavra secundaristas. Na verdade os movimentos, porque as ocupações em escolas não possuíam uma bandeira única, mesmo que os secundaristas espalhados pelas diversas escolas estivessem em sintonia, em cada escola há uma singularidade ou uma série delas, tanto pelo o que se luta como pelos corpos que nela, de alguma forma, habitam. 
Algumas bandeiras que podemos destacar como sendo aquelas com quais se luta eram / são: a) a reorganização das escolas públicas protagonizada pelo governo do estado de São Paulo na gestão de Geraldo Alckmin, a qual teve como desenrolar, a partir das ocupações, uma postergação e algumas iniciativas apelidadas de "por baixo dos panos" com fechamentos de salas, escolas e mudanças de turno; b) a dita reforma do Ensino Médio em nível nacional segundo medida provisória do governo de Michel Temer; c) a gestão compartilhada ou se preferir a privatização de escolas estaduais de Goiás para serem gerenciadas por Organizações sociais com uso de dinheiro público; d) a proposta de emenda constitucional número 241 (PEC 241 que depois mudou de número), que estipula teto para os gastos públicos com saúde, educação e assistência social, congelando as despesas do governo federal, reguladas por índices inflacionários, por até 20 anos; e) o "programa escola sem partido", proposta de lei que basicamente estipula deveres do professor em torno de sua conduta e maneiras de abordagem de temas como a política. Sem se demorar nessas bandeiras, uma vez que como já foi escrito, cada escola, cada ocupação possuía suas peculiaridades e não se deseja fazer generalizações. Citá-las nesse parágrafo foi uma estratégia de lembrança para algumas medidas, algumas ações que deflagaram em ocupações enquanto forma de resistir àquilo que se impunha e carregava intoleráveis contra os quais lutar.

As ocupações não eram, não são apenas de escolas, enquanto espaço físico - há um espaço também potente de circulação virtual, a internet, especialmente as redes sociais e as agências de notícias, que expõem certa ocupação porque interessadas numa produção de sentido para ela. Para além da exposição, as redes funcionam como forma de comunicação entre as escolas e entre os envolvidos numa ocupação. Nesse espaço virtual há uma ampla concorrência de atenções com as ocupações, no entanto sua potência está naquela produção de sentidos, também múltipla, em que elas ganham formas de dizibilidade e visibilidade (RANCIÈRE, 1995).

Múltiplos sentidos para o verbo ocupar estavam sendo gestados nessas novas experiências vividas pelos corpos-estudantes: a língua também revivia-se ali, no ciberespaço ocupado. Mas não só nele os verbos ocupar e resistir estavam sendo revividos com força na sociedade brasileira: parecia mesmo que esses verbos haviam sido engolidos e incorporados, que era nos corpos que estavam sendo reinventados os seus sentidos e sem sentidos (OLIVEIRA JÚNIOR, 2017, p. 7).

Tanto da internet como nas diferentes mídias, algo se tornou dizível em algumas notícias espalhadas pelo espaço: as escolas estavam mais limpas, uma vez que nas ocupações os estudantes se preocuparam com divisões de tarefas, dentre elas a limpeza. Tornou-se também visível em imagens circulantes. Algumas salas fechadas foram abertas e nelas muitos materiais, os mais diversos, foram encontrados sem uso, sem que houvesse ciência da existência por boa parte da comunidade escolar, "há um museu trancado que virou depósito de entulhos, há salas de aula vazias e lacradas há muito tempo, há material escolar novo empilhado e esquecido" (LACOMBE, 2016, s. p.). 
O que se quer mostrar com as desabilidades e visibilidades engendradas pelas ocupações em escolas não é apenas uma denúncia das condições em que as escolas públicas do Brasil se encontram, porque isso talvez com ocupação ou não já esteve desde sempre exposto por muitos lugares de circulação, essa informação é velha. Há, pois, nesse movimento de explorar o espaço da escola, de colocar os corpos em contato com os lugares e materiais escolares, uma forma de mobilização, que traz à tona um pensamento com a escola, com a educação. Gerir coletivamente o espaço e os materiais escolares, encontrar aquilo que se escondia por várias razões, pensar em formas de incluir esses materiais entulhados e esses espaços fechados - isso tudo é uma política de educação.

Esse argumento pode ganhar a via de um utilitarismo, em que as ocupações servem para que os secundaristas e a comunidade escolar digam e vejam o que há de errado com as disposições e contribuições materiais, dando-lhes outro destino. Mas talvez essa argumentação reduza demasiadamente o que se está chamando de uma política de educação. "A melhor maneira de matar um 'acontecimento' dessa ordem é reinseri-lo no encadeamento causal, reduzindo-o aos fatores diversos que o explicariam e o esgotam" (PELBART, 2016, s.p., grifo do autor). Sem excluir a possibilidade de outros destinos para os espaços e materiais, tal política quer um pouco mais, desdobrar aquilo que surge "ainda que de modo balbuciante ou embrionário, de novo, de inaugural, de fundante" (PELBART, 2016, s.p.) numa ocupação.

\section{OCUPAÇÃO E TERRITÓRIO}

Quando há uma abstenção por fechar um sentido para as ocupações, como por exemplo a reforma do ensino médio, além de se querer ressaltar sua heterogeneidade, é também porque cada uma delas está inserida num território distinto, o qual possui uma circulação de fluxos de informação, de demandas, de pessoas e interesses que ora se conjugam, ora se atritam e isso tem a ver com aquela política de educação.

Uma política menor, pode assim ser chamada tal política de educação, frisando que menor e maior ou "que macro e micro, aqui, não têm absolutamente nada a ver com 'grande' (a sociedade, o Estado... o todo) e 'pequeno' (o individual, o intra-individual, o grupal... a parte, a unidade) [...trata-se] de duas espécies radicalmente diferente de lógica" (ROLNIK, 2007, p. 59, grifos da autora).

A política maior, ou a macro política seria aquela que define um corte para qual é a reivindicação das ocupações em escola, tomando um formato de bandeira, com a necessidade de um programa e uma progressão entre fatos e relatos. Já uma política menor, ou micropolítica tem a ver com os balbucios dos corpos ali em ocupação que não sabem muito bem o que devem fazer e ainda sim fazem, as bandeiras e reivindicações da política maior também atravessam tais corpos, mas não é só por elas que se luta. Há intensidades, uma "lista de afetos não subjetivados, determinados pelos agenciamentos que o corpo faz, e, portanto, inseparáveis de suas relações com o mundo" (ROLNIK, 2007, p. 60, grifo da autora), por isso a singularidade de cada ocupação, um mundo formado pelo conjunto 
de afetos que os percorrem e que são tomados por movimentos também singulares que transformam, de alguma maneira, aquela escola-em-ocupação.

Os jovens - secundaristas - estão impregnados de algo com o qual eles também lidam ao ocupar, não somente essa linha dura do exemplo da reforma do ensino médio, mas as outras linhas que o compõem na forma como a educação brasileira tem sido tratada a tantos anos, se tornando um negócio, as leis sendo criadas muitas vezes distante das necessidades mais diretas de determinada comunidade, esse direcionamento de baixo para cima em que as políticas públicas ocasionalmente tomam entre político e população, outras linhas, outros intoleráveis mais diretamente relacionada a seus corpos como as sexualidades, as questões de gênero, os racismos e preconceitos, os machismos, fascismos e tantos ismos, enfim, uma série de possibilidades de coisas, algos, que estão impregnados nos corpos das ocupações e que contagiam essa política de educação que está se denominando menor.

Em fenômenos históricos como a Revolução de 1789, a Comuna, a Revolução de 1917, sempre há uma parte de acontecimento, irredutível aos determinismos sociais, às séries causais. Os historiadores não gostam muito desse aspecto: eles restauram causalidades posteriormente. Mas o próprio acontecimento está em desengate ou em ruptura com as causalidades: é uma bifurcação, um desvio relativamente às leis, um estado instável que abre um novo campo de possíveis (DELEUZE; GUATTARI, 2016, p. 215, grifo dos autores).

Uma vez que a política aqui é entendida como ocupação dos sentidos, distribuição do sensível e de um comum, ao preocupar-se com esses intoleráveis que tomam (o) corpo numa ocupação, o que se quer refletir é com a possibilidade de dar vazão a esses intoleráveis (ismos) e que encontra numa ocupação em escola um território possível para lhe garantir alguma forma de expressão, algum tipo de desengate com a utilidade dos gestos, uma maneira de comunhão e encontro dos corpos com aquilo que lhes afeta e guia as condutas, permitindo determinados movimentos e reprimindo outros.

\section{FORMAS DE EXPRESSÃO E OCUPAÇÃO}

No documentário ARTE | TERRITÓRIO² é possível extrair essa ideia que se quer trabalhar entre percepção de mundo e produção de formas de expressão, num território em ocupação. Esse território é o centro da cidade de São Paulo tomado, ocupado por artistas seja morando, seja por galerias ou espaço de artes, ateliês, seja transitando, enfim, muitas

2 Sinopse: documentário sobre artistas e espaços culturais que escolheram o centro de São Paulo para se situar, vivendo ou trabalhando. Os entrevistados abordam o viés histórico da região, os desafios e as vantagens de atuar nessa parte da capital paulista. Com Felipe Morozini, Maria Montero, Guilherme Wisnik e Paula Santoro. Ano: 2015. Duração: 12 minutos. Direção: Hugo Haddad. Produção: Red Bull Media House. Idioma: português. Disponível em: < http://www.archdaily.com.br/br/780767/arte-territ-rio-ocupacao-do-centro-de-sao-paulo-porartistas-e-retratada-em-documentario $>$. 
formas de ocupá-lo. Há algumas linhas que o documentário aponta de problemáticas que estão circulando por esse território e que os artistas produzem formas de expressá-las em suas artes, ou seja, ao ocupar aquele espaço composto por uma série de heterogeneidades, essas passam a também compor o processo criativo desses artistas.

Numa das falas, uma personagem diz que está impregnado da cidade e que estar impregnado nessa condição de artista não só reflete em suas referências estéticas, mas naquilo que é a matéria-prima de seu processo de criação, matéria-prima que está sujeita a uma forma de expressão. A personagem diz que está impregnada de barulho e é isso que ganha expressão em sua arte.

No entanto, é preciso frisar algo que se considera importante quando se está falando de arte: esse processo criativo entre algo que desperta a atenção do artista e aquilo que ele produz não é uma via direta, como num processo fabril em que as peças vão sendo colocadas uma a uma e no final se tem um produto - em arte, um mimetismo representacional. O que se está querendo pensar com um processo criativo em arte é de que sim algo desperta o artista, algo o acomete, algo de uma força incontrolável, a qual se torna vital na feitura de uma obra, uma performance, enfim, uma expressão artística.

Com relação ao território em questão - centro de São Paulo - uma das narrações que também se gostaria de trazer para essa escrita, trata-se da ideia de revitalização desse espaço. Na fala da personagem essa necessidade é falsa, uma vez que o centro é cheio de vida, não precisa que se traga a vida de volta. O termo revitalizar no dicionário sugere um novo impulso de vitalidade, revigorar, tornar vital e tem sido utilizado no meio arquitetônico e urbanístico no sentido de dar outras utilidades a determinado espaço, uma vez que se encontra degradado, ou com supostas inutilidades. No caso do centro, o documentário ressalta, há ali muita vida circulando, não é necessário revigorá-la e se há algum tipo de degradação ou inutilidade, elas são também oxigênio para suas criações, são parte integrante daquilo que lhes salta aos olhos e que se expressam nas artes.

O intuito, ao tomar as artes como exemplo, é de mostrar que há procedimentos capazes de dar formas de expressão para uma ocupação, uma criação entre pensamento, produção artística e maneiras de ocupar o centro de São Paulo. No entanto, não há o jeito mais certo disso ser feito, não há uma posologia que conte as gotas necessárias de arte para expressar uma ação, não há uma régua capaz de medir as forças que tomam o corpo ao criar e ocupar.

Visto isso, o que se pode escrever sobre uma ocupação? E ainda, se cada ocupação é uma singularidade, há uma escrita que as contemple?

Sim, se pode escrever muito sobre uma ocupação e muito foi escrito sobre as ocupações em escolas protagonizadas pelos secundaristas. Mas ao escrever sobre a chance de submeter os acontecimentos e produções daquele espaço e tempo numa razão suficiente, em causalidades que explicam os fatos encadeadamente é bem grande. Aquela revitalização necessária para que o espaço ganhe vida novamente, pode-se ver numa revitalização também de uma escrita que quer dar conta de revigorar uma ocupação, na qual as explicações sobre ela é que são capazes de animá-la. 
Diferentemente ao escrever com as ocupações, nunca haverá uma escrita que baste, nem outra forma de expressão que possa abarcar todas as singularidades e forças vitais que percorrem uma ocupação. Ao escolher escrever com já se sabe desde o início que há um fracasso da escrita e mesmo assim é preciso continuar para que aquelas forças incapturáveis ao menos continuem a vibrar, tracem linhas noutros espaços e tempos, que os brilhos se tornem faíscas que podem incendiar nessa escrita. É todavia bom lembrar que o risco de apagar está sempre à espreita.

\section{PENSAMENTO E PERCEPÇÃO DE MUNDO}

Gilles Deleuze (2006) escreve um texto chamado O método de dramatização3, em que questiona as perguntas que movem o pensamento e quais são os sentidos por elas movimentados. Para o filósofo perguntar sobre o que é? pode ser uma armadilha, na qual o pensamento é direcionado para uma resposta por trás da pergunta, como se se escondesse por trás de uma máscara, a qual a resposta a desvendaria. "A questão que é? prejulga o resultado da pesquisa, supõe que a resposta é dada na simplicidade de uma essência, mesmo que seja próprio dessa essência simples desdobrar-se, contradizer-se etc." (DELEUZE, 2006, p. 152, grifo do autor).

Tendo em vista isso, Deleuze sugere interpelar por outras questões: como?, quem? quando?, quanto?, onde?, as quais são mais potentes relativamente às Ideias. Há aquilo que rodeia a Ideia, um campo problemático no qual ela opera e é com isso que se lida ao estudar, pensar, refletir com esse campo, por isso a pergunta o que é? pode tornar-se inoperante diante dele e fechá-lo demasiadamente. Enquanto que as outras perguntas (como?, quem?, quando?, quanto?) são uma espécie de sondagem daquilo que emerge desse campo.

O que se gostaria de capturar desse texto, para além das muitas nuance filosóficas, riquezas de pensamentos que abarcam parte da história da filosofia, é a beleza de pensar por essas outras vias, que se desviam de um fechamento sobre a questão o que é? para então aventurar-se nos movimentos que os corpos, espaços, tempos, enfim, a série de elementos que compõem o campo problemático, aquilo que se deseja escrever com, na tentativa de perceber os sentidos envolvidos, "o sentido depende da distinção e da distribuição desses pontos brilhantes na Idéia" (DELEUZE, 2006, p. 135, grifo do autor), e que, ao acompanhar os movimentos, podem se destacar e inspirar um pensamento.

A beleza dessa escolha, que Deleuze nomeia como um método, é que, ao renunciar ao o que é?, e enfrentar outras questões, as quais traçam coordenadas espaço-temporais, corre-se menos risco de perder a multiplicidade da ideia, ou a multiplicidade que é uma ideia.

Tudo isso para esboçar um terreno, que se abstém de escrever sobre a ocupação e assim esquecer das múltiplas linhas que compõem e constituem uma ocupação em escola. Há insistências em eleger heróis e vilões, em tornar a ocupação num movimento ora salvacionista, ora de vandalização, entre outras, o que provoca um fechamento num

3 Texto que na verdade é uma conferência de 1967 que fora posteriormente publicada. 
único sentido e recai no julgamento entre certo ou errado, contra ou a favor, obstinada luta por colocar molduras.

As perguntas como?, quem? quando?, quanto?, onde? para as ocupações também não visam tornar o movimento personificado, uma tentativa de dar nome aos bois àqueles que participam desse movimento. "É que as singularidades do mundo servem de princípio para a constituição de individualidades: cada indivíduo envolve um certo número de singularidades e exprime claramente as relações entre elas, fazendo-o em relação ao seu próprio corpo" (DELEUZE, 2006, p. 138, grifo do autor). O que se persegue são as singularidades, as alianças entre os elementos, que não necessariamente são indivíduos, para que, a partir delas, se mobilizem afetos, ações, desdobramentos, enfim, uma política de educação, uma política menor.

Uma das iniciativas dos secundaristas foi de chamar pessoas, especialmente de fora da comunidade escolar, para dar uma aula, uma oficina, propor uma conversa, enfim, estar ali presente naquela ocupação, inclusive ocupando aquele lugar de outras maneiras, uma vez que as escolhas dos alunos é que estavam em jogo e não uma imposição das divisões de espaço e tempo escolar a que estão acostumados e são submetidos todos os dias.

A respeito da percepção de mundo, o artista que está no centro de São Paulo e o secundarista que estuda numa escola possuem cada qual em seu território percepções daquele espaço em que estão, e ao habitá-lo diferentemente, o artista morando, expondo, trabalhando em seu ateliê e o secundarista ocupando aquela escola, as percepções daquele espaço também se alteram. Por isso não se trata do que é a escola, mas de como?, quem?, quando?, quanto? está por ela circulando, investindo afetos, movimentando-se, criando formas de resistir e intervir no real daquele espaço.

Não é preciso trazer a vida de volta para o centro e a escola, há ali muita vida, mas talvez seja preciso dar passagem para ela, criar buracos e brechas pelos quais a vida possa passar, espaços e tempos em que ela se expresse - a palavra revitalizar poderia ser substituída por dar outras vitalidades, ou dar passagem para as vitalidades daquele espaço e tempo escolares, daquele espaço e tempo urbanos.

\section{CORPO, AFETO E OCUPAÇÃO}

Eu queria insistir nesse aspecto tão importante, a meu ver - um acontecimento como o do ano passado [as ocupações em escola], com seu cortejo de arbítrio, violência, abuso, mas também de mobilização, iniciativa, afirmação, representou um corte abrupto na percepção social sobre o ensino, a escola, a polícia, o Estado, o poder, o desejo (PELBART, 2016, s.p.).

É interessante perceber nesse texto de Peter Pál Pelbart esse caráter ambíguo das ocupações, um paradoxo entre liberar e conservar. Há algo que se quer conservar ao ocupar - o direito à educação, por exemplo, mas também há algo que se quer mudar, modificar, transformar - a participação nas decisões políticas em torno das questões educacionais. 
Ao tomar o espaço escolar e as lutas que nele ocorrem, lutas que não se resumem à ocupação, lutas que estão no cotidiano, nos intoleráveis que transitam e muitas vezes colam num senso comum ${ }^{4}$, é sempre bom estar atenta ao que se conserva e libera, às políticas macro e micro, maior e menor e em como elas atingem os corpos, quais são os afetos que elas liberam e conservam.

Lembrando de maneira um tanto simplória que um afeto, enquanto conceito filosófico espinosano, refere-se a uma transição dos estados de um corpo, ou seja, a partir de algo que acomete um corpo, ele passa de um estado precedente a outro por uma indução, que implica num aumento ou diminuição de sua potência de agir. Experimenta-se algo no corpo que o faz mudar de um estado a outro. E um corpo é definido por essa potência de afetar e ser afetado. O afeto que aumenta a potência de agir é um afeto alegre e o que reduz é um afeto triste. O corpo não é capaz de controlar esses afetos, todavia pode avaliar aquilo que lhe convém, expresso pelo aumento de sua potência de agir - afetos alegres e repulsar o que não Ihe convém, a diminuição de sua potência de agir - afetos tristes (DELEUZE, 2002). Portanto, não se trata apenas de sentimentos, os afetos são paixões, combustíveis para a vida, as ações.

Pelbart (2016) escreve de uma cisão na percepção social e elege alguns elementos que mudaram de posição: ensino, escola, polícia, Estado, poder, desejo. Passou-se, então, de um estado a outro, mesmo que não haja algo nomeável, palpável para dizer foi isso que causou essa mudança no processo. Ou, na verdade, muitas escritas e falas escolheram muitos "issos" para determinar e identificar o movimento e sua causa. Essa escrita ainda fica na indeterminação e com a hipótese de que os corpos puderam avaliar aquilo que Ihes convinham ou não e mobilizaram ações entre aquilo que é intolerável, mesmo que não se nomeie e desejável, ainda que não se saiba como fazê-lo exatamente.

Não aceitar "a escola disciplinadora, a hierarquia arbitrária, a degradação das condições de ensino" (PELBART, 2016, s.p.) e convocar forças para "a inversão das prioridades entre o público e o privado, a primazia da voz dos estudantes, a possibilidade de imaginar uma outra escola, um outro ensino, uma outra juventude, inclusive uma outra sociedade!" (PELBART, 2016, s.p.), esse é um balanço que se pode esboçar com as ocupações em escolas - aquilo que aconteceu entre corpo, afeto e mobilização.

Só que ao escolher permanecer na indeterminação das causas, outro pormenor também é convocado. Os resultados de uma ocupação não são o foco desse trabalho, isso é uma escolha e também uma consequência da indeterminação. Contudo, não ter um resultado não se trata de menosprezar a avaliação das forças que estavam e estão em jogo - mas, ao avaliar, colocá-las, pois, dentro de campo sem a prioridade da vitória. Perguntar-se: quais são os afetos que essas linhas de força contagiam? Em quais colocar atenção? Em quais investir e quais deixar passar? Talvez seja esse o papel não só dessa escrita, mas do professor e da professora que convivem com esses alunos. Acompanhar

4 “Qualquer hábito, qualquer repetição de um ato por mais absurdo que seja, rapidamente é absorvido: o excepcional transforma-se em poucas semanas; em certas circunstâncias bastam dias para que o monstruoso e o informe se faça normalidade e hábito" (Tavares, 2013, p. 7-8). 
as forças e afetos que contagiam os corpos desses secundaristas, avaliá-las no sentido de perceber aquelas que se dirigem ao que está instituído, ao que é um retrocesso, e aquelas que viabilizam um comum, compartilhamentos e aumento da potência de agir.

Se é um lugar-comum dos estudantes no espaço escolar, qual é o deslocamento que eles provocaram ao estarem ali em ocupação?

Tal pergunta não possui apenas uma resposta. É possível afirmar que os secundaristas inventaram um modo distinto de estar naquele espaço, isso de maneira extensiva, ao ocupá-lo, e intensiva, ao dar vazão aos intoleráveis que foram de alguma forma expostos. Espaço escolar e secundaristas ganham outros contornos, lugar em que as exigências dos direitos podem ganhar expressão, em que os deveres e responsabilidades com e por aquele espaço alteram a maneira de habitá-lo. Essa com certeza é uma política de educação, uma política menor.

Por isso abster-se de resultados elencados, especialmente aqueles quantitativos, e preferir, pois, a indeterminação e um apontamento avaliativo e interrogativo das forças que podem ter contagiado uma política entre corpo, afeto e ocupação. Propor questões mais do que (re)soluções.

\section{OCUPAÇÃO E EDUCAÇÃO FÍSICA}

Qual a função criadora do educador, da educadora? Qual a potência da educação e da educação física?

Partindo do senso comum de que o espaço escolar é aquele que estabelece a garantia de ser do mesmo jeito, de fazer as coisas da mesma forma por todas as personagens da comunidade escolar. Os alunos e alunas devem aprender da mesma forma todo o conteúdo proposto. Os professores e as professoras devem ensinar da mesma forma, independente de seu conteúdo. Os diretores e as diretoras além de dirigirem, punem aqueles que saem das formas estabelecidas. Os pais e as mães são aqueles que devem contribuir com a educação das crianças, sem, entretanto, atrapalhar o andamento dos processos escolares. E assim por diante - a merenda feita da mesma forma, a limpeza feita da mesma forma etc. - há um funcionamento que insiste em persistências e costuma recusar aquilo que foge dos eixos.

As ocupações com toda certeza instauraram algum tipo de desfuncionamento. Os papéis foram recolocados, as funções, os espaços, os materiais, enfim, tudo virou de cabeça para baixo. Alguns professores relataram que se surpreenderam com as atitudes tomadas por certos estudantes, os quais se mostravam alheios e/ou passivos em suas aulas (LACOMBE, 2016). E, nessa escrita, todos esses movimentos estranhos estão sendo chamados de uma política menor de educação.

Então, a função criadora, a potência da educação está em manter as coisas nos trilhos ou virá-las de ponta cabeça?

Já fora chamada a atenção para as coisas que se querem conservar e aquelas que se querem modificar dentro de uma ação, como uma ocupação em escola, e de que sempre há algo nesses dois polos. Isso não significa um estabelecimento de uma dicotomia entre 
conservação e liberação, mas, isso sim, uma espécie de escala em que várias matizes são possíveis.

Entre liberação e conservação, a pergunta que Ihe cabe escapa daquilo que é uma e outra, para criar outras perguntas como: liberar por quê? Quando? Conservar o quanto? Como liberar e conservar? - perguntas que possam dramatizar, colocar em movimento essa escala de matizes variadas.

Ao direcionar a atenção para os afetos que percorrem um corpo e aquilo que the potencializa ou não a vida, os intoleráveis virão à tona e junto com eles a possibilidade de produzir uma avaliação das forças que compõem cada intolerável e também as forças que compõem aquilo que lhes combate.

Os processos educativos que estão por todas as partes, assim como aquilo que se deseja liberar e conservar. Trabalhar a percepção das coisas e de como elas são colocadas em movimento no mundo - talvez seja essa a função criadora e a potência da educação.

O professor e a professora de educação física possuem o privilégio de serem aqueles que, usualmente e até num senso comum, são responsáveis pelos corpos dos alunos e alunas. Privilégio no sentido em que essa exploração, investigação entre corpo e afeto pode ser nesse espaço-tempo da aula de educação física potencializado, conservando a responsabilidade pelos corpos e liberando a atenção para aquilo que os toma.

Há inúmeros conteúdos presentes entre esporte, ginástica, atividades rítmicas e expressivas, lutas, jogos. E à medida que esses conteúdos são colocados num contexto de aula, ali surgirão também inúmeras questões que perpassam a vida em sociedade. São com essas questões, impulsionadas por tais conteúdos que a educação física é responsável.

Um professor, uma professora e uma educação são aqueles que acolhem os gestos de quem se trabalha e reorienta se for necessário, o que implica uma analítica embutida nesses gestos que são ao mesmo tempo extensivos, na atualidade dos encontros, e intensivos, na qualidade dos afetos.

A disponibilidade deve estar em ir aos encontros, não somente na circunscrição do espaço-tempo de uma aula, mas na "fonte e [n]a matéria mesma do contemporâneo - a vida (em) comum" (PELBART, 2016, s.p.). A exemplo de Michel Foucault ao estudar o poder e não se dirigir exclusivamente aos governos no decorrer da história, mas vendo-o em toda parte com seus dispositivos de funcionamento atuando por todo canto. Ir aos encontros, já que as liberações e conservações estão em vários lugares, ir para produzir uma sondagem da qualidade de tais encontros. Professores e educação disponíveis porque implicados na tarefa de sondar a qualidade dos afetos que compõem uma ação, um movimento, um gesto e produzir um repertório capaz de intervir e interferir nas questões que surgem no espaço-tempo escolar.

nosso tempo inventou modalidades de servidão inauditas. E o que os secundaristas nos ensinaram é que também as formas de resistência se reinventam. A horizontalidade e a ausência de centro ou comando nas ocupações e nas manifestações dramatizaram uma outra geografia da conflitualidade (PELBART, 2016, s.p.). 
Servidões que nas palavras dessa escrita são os intoleráveis. A horizontalidade ensinada nas ocupações pode ser vivida no cotidiano escolar de outras formas. Horizontalidade que não quer dizer ausência de responsabilidades específicas, mas ausência de subordinações. Assim a relação entre professor e aluno pode sofrer modificações.

A aprendizagem e o ensino podem perder a direção vertical, em que de um lado se detém um conhecimento o qual será transmitido, e do outro se recebe passivamente o conhecimento que está localizado alhures.

Ao frisar essa perda de coordenada para a aprendizagem e o ensino, ela tem propriamente a ver com frisar a ideia de encontro ${ }^{5}$ uma implicação nas relações. Relação entre as personagens da comunidade escolar e relação de cada uma delas entre seus corpos e a vida.

O que se quer dizer com encontro é da ordem de uma experiência comum que, no entanto, sofre um abalo e nela algo toca o corpo diferentemente. Há o ordinário das relações triviais e há um extraordinário que provoca outros sentidos para o vivido. Um encontro é a erupção de uma sensibilidade para com aquilo que o corpo entra em contato.

aprender evolui inteiramente na compreensão dos problemas enquanto tais, na apreensão e condensação das singularidades, na composição dos corpos e acontecimentos ideais. Aprender a nadar, aprender uma língua estrangeira, significa compor os pontos singulares de seu próprio corpo ou de sua própria língua com os de uma outra figura, de um outro elemento que nos desmembra, que nos leva a penetrar num mundo de problemas até então desconhecidos, inauditos. E a que estaríamos destinados senão a problemas que exigem até mesmo a transformação de nosso corpo e de nossa língua? (DELEUZE, 2000, p. 317).

Por isso insistir que a educação física envolve não só os conteúdos aos quais ela está destinada - esporte, ginástica, atividades rítmicas e expressivas, lutas, jogos - mas aquilo que implica os corpos no encontro com tais conteúdos. Estar disponível e tornar a aula disponível para os signos que envolvem essas práticas.

Voltando para as ocupações - se elas puderam fazer eclodir uma outra sensibilidade dos corpos ao ocupar aquele espaço-tempo escolar, então isso tem tudo a ver com a educação física que se está pensando e escrevendo com. Está implicado nessas outras relações entre corpo e espaço escolar as questões especialmente referentes aos intoleráveis e em como os secundaristas criaram saídas para lidar com eles.

A horizontalidade das relações é uma dessas saídas e torna-se primordial pensá-la no trato entre aluno e professor. A maneira como tiveram de lidar com as mídias, seja

5 Especialmente pensando com a filosofia de Gilles Deleuze tanto só, como em companhia de Félix Guattari em inúmeros de seus textos. Em relação à aprendizagem, Deleuze (2010, p. 4, grifos do autor) escreve: "Aprender diz respeito essencialmente aos signos. Os signos são objeto de um aprendizado temporal, não de um saber abstrato. Aprender é, de início, considerar uma matéria, um objeto, um ser, como se emitissem signos a serem decifrados, interpretados. Não existe aprendiz que não seja 'egiptólogo' de alguma coisa. Alguém só se torna marceneiro tornando-se sensível aos signos da madeira, e médico tornando-se sensível aos signos da doença. A vocação é sempre uma predestinação com relação a signos. Tudo que nos ensina alguma coisa emite signos, todo ato de aprender é uma interpretação de signos ou de hieróglifos. A obra de Proust é baseada não na exposição da memória, mas no aprendizado dos signos". 
para intercomunicação, seja para chamamentos e acordos, bem como os jornais e outros meios de comunicação, explorando a horizontalidade, não elegendo nenhum porta-voz e escolhendo aqueles meios com menos pretensão de distorcer suas palavras. A gestão do espaço para reivindicar direitos, estendê-los, criar composições entre pessoas e coisas e experimentar viver num coletivo formado de heterogêneos que buscam algo em comum.

\section{TRAFEGANDO}

Não foi por acaso a escolha da palavra trafegar para o título desse texto e seu gerúndio trafegando para esse subtítulo. Etimologicamente ela quer dizer fazer passar de um lado a outro. A escrita que percorre essas linhas partiu de um estado de coisas - as ocupações em escolas - e uma série de outras palavras que acompanham tais ocupações: formas de expressão; pensamento; percepção de mundo; corpo; afeto; educação; território e educação física para tentar fazê-las passar, todas essas palavras, de um começo mais caótico, em que as relações ainda não estavam formadas, para em cada uma das partes ir criando conexões possíveis entre os termos. Tudo isso para também fazer passar uma ideia de ocupação e política que escapem de um utilitarismo exacerbado, em que as decisões políticas tomadas numa ocupação possuíssem apenas determinado fim ensimesmado, em que causa e efeito estivessem bem claras e expostas, sem que dúvidas e vacilos fossem liberados.

Justamente a aposta é na indeterminação, num corpo trêmulo, em secundaristas que ainda não viveram muito tempo cronológico, mas que já entendem que a vida em sociedade é recheada de muitos intoleráveis, direitos e deveres que não estão dados só porque escritos numa legislação, e que eles precisam ser conquistados todos os dias.

Por isso um investimento nos afetos, numa micropolítica dos afetos, com a qual se avalia as forças que percorrem tal e tal território social.

A conexão com as artes, no caso do documentário sobre o centro de São Paulo, é pela possibilidade de encontrar nas artes algumas maneiras de olhar diferentemente. A arte dá a ver muitas coisas, insere-se na produção de uma percepção de mundo e um pensamento, ela tem a ver com dar formas de expressão para aqueles intoleráveis que são de alguma forma revelados.

A pergunta que cabe dentro desse ritmo de escrita e que dramatiza uma política menor de educação é: como os mais ordinários desejos dos jovens secundaristas ganham expressão numa ocupação?

Essa pergunta não é para ser respondida, ela é para ser indagada pelos professores que convivem com esses jovens diariamente, ela é para ser pensada por eles, ser colocada em movimento não só nas ocupações, mas no cotidiano. O professor, a professora são aqueles que, de alguma forma, observam esse movimento dos desejos na latência e nas formas de expressão desse cotidiano.

E na figura do professor/ professora de educação física, que chama para si a responsabilidade de ser aquele/ aquela que cuida dos corpos desses estudantes, essa figura pode estar atento/ atenta a esses desejos. "A imaginação política não é uma esfera sonhadora 
e desconectada da realidade, ao contrário, é precisamente a capacidade de se conectar com as forças reais que estão presentes numa situação dada, as forças do entorno, mas também as forças vossas" (PELBART, 2016, s.p.). Forças que circunscrevem os gestos aos quais é preciso estar à espreita, e que estão também nesse gesto de tomar a educação física pelos afetos.

Se a educação física é aquela que sempre está alijada dentro do sistema educacional, vide a reforma do ensino médio, se a não importância é algo a acompanha, talvez a saída seja impulsionar essa potência ao se tornar responsável pelo corpo e os afetos numa política de educação que se faz nos encontros - "uma das definições de ética é a de estar à altura do que nos acontece" (PELBART, 2016, s.p.) - preparar-se, pois, enquanto profissional dessa área, na sondagem das qualidades dos afetos que compõem um encontro, para estar à altura dessa responsabilidade.

\section{REFERÊNCIAS}

DELEUZE, Gilles. Diferença e repetição. Trad. Luiz B. L. Orlandi e Roberto Machado. Lisboa: Relógio d'Água, 2000.

. Espinosa: filosofia prática. Trad. Daniel Lins e Fabien Pascal Lins. São Paulo: Escuta, 2002.

. O método de dramatização. In: DELEUZE, Gilles. A ilha deserta: e outros textos textos e entrevistas (1953-1974). Edição preparada por David Lapoujade. Organização da edição brasileira e revisão técnica de Luiz B. L. Orlandi. São Paulo: Iluminuras, 2006. p. 129-154.

. Proust e os signos. Trad. Antonio Piquet e Roberto Machado. - 2. ed. - Rio de Janeiro: Forense Universitária, 2010.

; GUATTARI, Félix. Maio de 68 não ocorreu. In: DELEUZE, Gilles. Dois regimes de loucos - textos e entrevistas (1975-1995). Edição preparada por David Lapoujade. Trad. Guilherme Ivo. Revisão técnica: Luiz B. L. Orlandi. São Paulo: Ed. 34, 2016. p. 215-219. LACOMBE, Milly. O que podemos aprender com as ocupações das escolas de São Paulo.

Revista Galileu. 5 de maio de 2016. Disponível em: < http://revistagalileu.globo.com/ Revista/noticia/2016/05/o-que-podemos-aprender-com-ocupacoes-nas-escolas-de-saopaulo.html >. Acesso em 24 de março de 2017.

OLIVEIRA JÚNIOR, Wenceslao Machado. Uma manhã (des)ocupada. ETD - Educação Temática Digital, Campinas, SP, v. 19, p. 1-8, mar. 2017. Disponível em: < http:// periodicos.sbu.unicamp.br/ojs/index.php/etd/article/view/8648457>. Acesso em 24 de março de 2017.

PELBART, Peter Pál. Carta aberta aos secundaristas. Disponível em: < http://outraspalavras .net/brasil/pelbart-tudo-o-que-muda-com-os-secundaristas/>. Acesso em 13 de maio de 2016. RANCIÈRE, Jacques. Políticas da escrita. Trad. Raquel Ramalhete. Rio de Janeiro: Ed. 34, 1995. 
julho/2018

ROLNIK, Suely. Cartografia sentimental: transformações contemporâneas do desejo. Porto Alegre: Sulina; Editora da UFRGS, 2007.

TAVARES, Gonçalo M. Matteo perdeu o emprego. Rio de Janeiro: Foz, 2013.

Recebido em: Abril/2017

Aprovado em: Agosto/2017 